\title{
Policy Voting, Projection, and Persuasion: An Application of Balance Theory to Electoral Behavior
}

\author{
Max Visser \\ Department of Public Administration and Political Science, University of \\ Twente, The Netherlands
}

In this article differences between rational, policy-based, and rationalized voting are discussed, and it is argued that these forms of electoral decision making are not properly analyzed in existing electoral studies. Policy voting, persuasion, and projection are then redefined as three possible ways of restoring balance among imbalanced triads of political beliefs and attitudes. With the help of the Chernobyl nuclear plants issue it is shown that persuasion and projection are far more important ways of restoring balance than policy voting.

KEY WORDS: voting; projection; persuasion; balance theory

\section{INTRODUCTION}

It has been an important assumption of certain normative democratic theories and the rational choice perspective alike that the voting choice is rational. The voter, making up his mind for election day, informs himself on the important policy issues of the campaign, compares his own issue opinions with the opinions of the candidates (or parties) at stake, and votes for the candidate nearest to his own issue positions. From the beginning of electoral research, however, this assumption of a rational, policy-based voting decision was challenged through the discovery of psychological mechanisms confounding the voters' and candidates' issue opinions, which mechanisms became known under names like rationalization, assimilation, contrast, projection, and persuasion. In modern voting research, however, these seemingly irrational processes continued to be analyzed in conjunction with rational voting, sustained by advanced methodology which made it possible to distinguish empirically the real policy voters from the "ratio- 
nalizers." In a theoretical sense, though, the rational and irrational processes remained separated, each drawing its rationale from a different body of theory.

In this article I will discuss some current models of voting behavior and their treatment of rational and rationalized voting. Finding these models wanting in theoretical coherence, I propose a psychological theory of the voting action in which rational and rationalized voting receive a uniform treatment. The specific acts of policy voting, persuasion, and projection may be analyzed as parts of more general processes concerning the origin, maintenance, and resolution of psychic conflict, which processes ultimately determine the voting action. After discussing these processes in terms of Heider's balance theory, I will show in a quasiexperiment how psychic conflicts are maintained or resolved through policy voting, projection, and persuasion, and how party choice is affected. Finally, some conclusions are drawn.

\section{THE RATIONAL AND THE RATIONALIZED VOTE}

In a classic article, Brody and Page (1972) outlined the differences between rational voting and rationalized voting. A rational, policy-based choice of a candidate (or party) would follow Downs's (1957) requirement that the voter first decides on his own position on the important political issues of the day, compares his issue stands to those of the available candidates, and then decides to vote for the candidate nearest to him on most issues; the causal chain would thus run from issue positions to the voting action. The rationalized vote implies a reversal of this causal order: the choice of the candidate influences the issue positions of the voter.

Such a rationalization may occur in two forms. First, it may take the form of projection. The voter favors a candidate on other grounds than issue position and assumes that the favorite candidate agrees with him on the issues (Brody \& Page, 1972); at the same time a "reverse" projection may occur to the extent that the voter ascribes to a candidate, whom he already dislikes on other grounds, those issue positions that the voter himself rejects (Markus \& Converse, 1979).

Second, rationalization may take the form of persuasion. The voter decides on a candidate for other reasons than issue positions and conforms his own issue opinions to those of the selected candidate (Brody \& Page, 1972); again a reverse form of persuasion may be discerned in that a voter adapts his own issue stands in contradiction to those of a candidate already negatively evaluated on other grounds (Markus \& Converse, 1979). ${ }^{1}$

'Note that these processes of rationalization may also be described in terms of assimilation and contrast. Persuasion involves the assimilation of the issue opinions of the voter's favorite candidate to the voter's own positions; projection is the assimilation of the voter's own issue stands to those of his liked candidate. Their reversals indicate a contrasting of the voter's own issue positions to those 
In a number of subsequent articles it was attempted to separate the rational voters from the rationalizers (Page \& Jones, 1979; Markus \& Converse, 1979; for a review see Niemi \& Weisberg, 1984). In a methodological sense, the processes of projection and persuasion imply reciprocity in the causal relationships between the different factors leading to the voting choice, a reversal of the causal order which the different researchers capture through the specification of nonrecursive, simultaneous equation models. Only Markus and Converse, however, are able to distinguish between projection and persuasion effects, through the use of panel data.

While rationalizing effects thus could be modeled and shown in an empirical sense, much less effort was put in a theoretical explanation of these phenomena. Page and Jones, for example, loosely refer to the social-psychological studies on selective perception, as well as to rational choice theories dealing with decision making under conditions of incomplete information. Markus and Converse posit the "rational" decision rule that the voter will vote for the candidate of whom he expects the smallest subjective loss, and combine this rule with some nonspecified social-psychological theories of policy voting. Nowhere, however, are the insights from rational choice theory or social psychology combined in one integrated framework; the authors typically stay close to the variables employed, emphasizing methodological ingenuity over theoretical coherence.

In this article I will reverse this emphasis. First, I propose to integrate projection and persuasion, together with policy voting, into a social psychological approach to the voting action. Secondly, I will attempt to demonstrate the existence of rational and rationalizing voting tendencies in a relatively simple and straightforward quasiexperiment.

In a psychological sense, policy voting, projection, and persuasion may be regarded as parts of more encompassing processes regarding the origin, maintenance, and resolution of psychic conflict. Normally the person facing the election holds multiple opinions and attitudes about the different elements of politics (issues, candidates, parties, etc.), which opinions and attitudes may be more or less in conflict with one another, pulling the person toward different candidates.

The degree to which this conflict is actually experienced and the modes of conflict resolution that are chosen differ from person to person. We can broadly specify three interrelated conditions which are significant in this respect.

The first condition refers to the degree of differentiation and integration of

of the disliked candidate (reverse projection), or a contrasting of the issue stands of the rejected candidate to the voter's own positions (reverse persuasion). Although in essence referring to identical psychic processes, the four mechanisms derive from different psychological schools: projection originates from the psychoanalytic study of defense mechanisms, persuasion from the Yale studies in communication, while assimilation and contrast come from Gestalt theory, being two different expressions of the tendency toward a "good" Gestalt in the perceptual field (Koffka, 1935, pp.106ff). 
the person's "field" of political elements. Differentiation indicates the number of political elements that the person recognizes, integration implies the number of connections which the person sees between these elements (Luskin, 1987; Sniderman et al., 1991). Only when the person knows or perceives that one element (such as a candidate) belongs to or is connected to another element (such as a party) is it possible for him to detect possible inconsistencies in his evaluations of those elements: a favorable attitude toward candidate $\mathrm{X}$ and a negative attitude toward that candidate's party $\mathrm{P}$ cannot be in conflict as long as the person does not recognize that $X$ and $P$ belong together.

The second condition pertains to the person's actual tolerance of psychic conflict, which tolerance is commonly regarded as a deeper-lying property of his personality; it refers to the degree to which the person's orientation to the external environment is influenced by internal psychic forces. A person whose personality is dominated by unresolved subconscious tensions tends to adopt a rigid and stereotypical view of his environment, in which there is no place for ambiguity or conflict. The less tolerant of conflict the person is, the more stringent his attempts to reduce the conflict will become, in extreme cases bordering on the pathological (Adorno et al., 1950; Berelson et al., 1954; Frenkel-Brunswik, 1949; Festinger, 1957; Lane, 1973).

Finally, the third condition is the degree of ambiguity inherent in the stimulus situation. For example, candidates (or parties) do not always find it advantageous to be straightforward in their issue positions, especially not in the case of hotly disputed issues. The less clear-cut their positions, the less their potential for conflict with other elements of politics (Berelson et al., 1954; Page, 1976; Page \& Brody, 1972).

To the degree that these conditions are operative, the person will experience the conflict among his opinions and attitudes as more or less unpleasant or painful, and consequently he will more or less attempt a resolution of the conflicting forces; in other words, he will strive for consonance, balance, or congruity among his cognitions and evaluations (Festinger, 1957; 1964; Heider, 1946; Rokeach, 1960). Projection, persuasion, and policy voting are to be regarded as three possible mechanisms through which a resolution of conflict may be achieved. This becomes clear once we have recast the previous discussion of rational versus rationalized voting in terms of Heider's balance theory.

The Austrian-American psychologist Fritz Heider was the first to generalize the Gestalt principles of visual perception to the field of human behavior, conceptualizing the tendency toward "good" form that characterizes perception as a tendency toward balance in human relations. A person $\mathrm{P}$ may have a relation to another person $\mathrm{O}$ and to some nonpersonal entity $\mathrm{X}$ (thing, idea, etc.), and these relations may have an evaluative character ( $\mathrm{P}$ likes $\mathrm{O}, \mathrm{P}$ hates $\mathrm{X}$ ) and a "unit" character ( $P$ owns $X, P$ causes $X, O$ is proximal to $X$, etc.), whereby $P, O$, and $X$ are all part of P's field (or life space). According to balance theory, a balance 
between these three entities exists when all three relations are positive in all respects, or when two are negative and one is positive. "If no balanced state exists," Heider asserts, "then forces towards this state will arise. Either the dynamic characters will change, or the unit relations will be changed through action or through cognitive reorganization. If a change is not possible, the state of imbalance will produce tension" (Heider, 1946, pp. 107-108).

Essential in balance theory is that the given whole of relations is not in a static condition, but that it is a momentary resultant of different forces driving in divergent or convergent directions. In such a dynamic system, any change in one part will have repercussions for the whole, and conversely the nature and function of one part are determined by their relationship to the other parts making up the whole. This dynamic character also has a time aspect: a change of part $X$ at time $\mathrm{T}$ will not only affect $\mathrm{O}$ at time $\mathrm{T}$, but also $\mathrm{P}$ at $\mathrm{T}+1$.

Principles of balance may be readily extended to the field of voting behavior. The processes of projection, persuasion, and policy voting then may be redefined as three possible ways in which the voter seeks to balance his beliefs and attitudes about the political world. Consider a triad consisting of voter $\mathrm{V}$, candidate C, and issue opinion I, as in Figure 1. Suppose further that voter V positively evaluates candidate $\mathrm{C}$, favors issue position $\mathrm{I}$, but perceives that $\mathrm{C}$ rejects position I. This voter is in a state of imbalance, which creates tensions toward change among the triad's elements. We define a change in the relation V-I, with no changes in the other relationships, as persuasion: V adopts C's position on issue $\mathrm{I}$. A change in the relation $\mathrm{C}-\mathrm{I}$, with no other changes in the triad, amounts to projection: $\mathrm{V}$ perceives $\mathrm{C}$ as adopting V's position on $\mathrm{I}$. Another possibility, a change in the relation $\mathrm{V}-\mathrm{C}$ without other changes, may be defined as policy voting: $\mathrm{V}$ changes his evaluation of $\mathrm{C}$ in the light of $\mathrm{V}$ 's own position of I and his knowledge of C's deviating stand on I.

The occurrence of imbalanced states, the degree to which they are resolved into balanced states and whether balance is achieved through persuasion, projection, policy voting or some other change ultimately are empirical questions. In the next paragraph I will report on an empirical investigation of these matters, concerning the issue of nuclear energy. Two points have our attention here. Given the tendency toward balance which Heider posits, we are interested to see whether a balanced state is actually more stable than an imbalanced one. Second, we wonder how changes come about in the two states, and to what extent the imbalanced state is altered through projection, persuasion, policy voting, or in some other way.

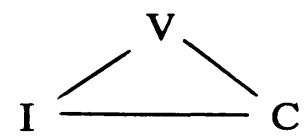

Fig. 1 


\section{CHERNOBYL AND THE NUCLEAR ISSUE}

Following the energy crisis of the mid-1970s, in the Netherlands the question arose of which alternative sources of energy should be exploited instead of oil. The political discussion quickly centered on nuclear energy, and by 1980 the benefits and disadvantages of nuclear power had become a subject of a lively public debate. In 1985 the Dutch government decided to enlarge the number of nuclear plants, after which decision the public interest in nuclear power diminished somewhat. The issue of nuclear power plants forcefully regained the public's attention, however, when on April 30, 1986, the newspapers carried the first news of the nuclear disaster in Chernobyl. Although thousands of miles away, the nuclear fallout resulting from the meltdown of the Russian power plant reached large parts of northwestern Europe, bringing home the dangers of nuclear energy to many people in a clear and unambiguous way. As a result, Dutch public opinion intensified its opposition to nuclear energy, and any extension of the number of nuclear plants ceased to be viable political alternative for years to come (Van Holsteyn, 1987).

Tragic as the accident was, its timing presents us with a good case to test different aspects of balance theory. On May 21, 1986, the general elections for the Second Chamber of the Dutch Parliament were due, and the workgroup in charge of the Dutch National Election Study had just before the Chernobyl disaster completed its first wave of survey interviews (Van der Eijk et al., 1988). The interviews contained questions of the respondents' opinions about nuclear power plants, their perceptions of the stands of the four major parties on this issue, and their voting intention (see Appendix for more details). Immediately after the elections the second wave of interviews was carried out, again including the questions mentioned and the respondents' votes.

\begin{tabular}{|c|c|c|c|c|}
\hline & \multicolumn{2}{|c|}{ March-April } & \multicolumn{2}{|c|}{ May-June } \\
\hline & Mean & (S.D) & Mean & (S.D) \\
\hline $\begin{array}{l}\text { Perception of VVD } \\
\text { (N) }\end{array}$ & $\begin{array}{l}2.5 \\
(880)\end{array}$ & $(1.7)$ & $\begin{array}{l}2.8 \\
(785)\end{array}$ & (1.5) \\
\hline $\begin{array}{l}\text { Perception of CDA } \\
\text { (N) }\end{array}$ & $\begin{array}{l}2.6 \\
(913)\end{array}$ & $(1.6)$ & $\begin{array}{l}3.4 \\
(820)\end{array}$ & (1.5) \\
\hline $\begin{array}{l}\text { Percption of D66 } \\
(\mathrm{N})\end{array}$ & $\begin{array}{l}4.7 \\
(710)\end{array}$ & $(1.5)$ & $\begin{array}{l}5.1 \\
(647)\end{array}$ & (1.4) \\
\hline $\begin{array}{l}\text { Perception of PvdA } \\
(\mathrm{N})\end{array}$ & $\begin{array}{l}5.8 \\
(911)\end{array}$ & $(1.8)$ & $\begin{array}{l}6.4 \\
(828)\end{array}$ & (1.3) \\
\hline $\begin{array}{l}\text { Voters' opinion } \\
\text { (N) }\end{array}$ & $\begin{array}{l}4.6 \\
(1,028)\end{array}$ & $(2.2)$ & $\begin{array}{l}5.4 \\
(869)\end{array}$ & (1.8) \\
\hline
\end{tabular}

Note: see Appendix for information on variables. N's include those respondents stating an intention in wave 1 to vote for one of the major four parties, PvdA (Socialists), CDA (Christian Democrats), VVD (Liberals) and D66 (Democrats).

Fig. 2. nuclear issue opinions and perceptions of party positions, March-June 1986 
In Figure 2 the sequence of events is presented schematically, together with the opinions of the respondents involved. It can be seen that the respondents move almost a full position in the "no" direction, while their opinions at the same time become more homogeneous. Respondents also perceive the four major parties as taking a more antinuclear stand, although in both waves CDA and VVD are consistently viewed as proponents of more nuclear power plants, and PvdA and D66 as opponents of these plants.

This course of events presents us with a research set-up which comes close to a natural experiment without a control group (Shively, 1980): in wave 1 the respondents' voting intentions, nuclear issue opinions, and perceptions of party positions are measured, and respondents are divided in a balanced and an imbalanced group; the Chernobyl accident, the electoral campaign, and the election act as stimuli on the respondents, presumably sharpening their awareness of possible imbalances among their opinions, perceptions, and voting intentions; in wave 2 , right after the elections, all pertinent variables are measured again, and tendencies toward (im)balance can be ascertained among the two groups of voters.

The concept of balance may be applied as follows. Consider the triad in Figure 1, consisting this time of voter $\mathrm{V}$, party $\mathrm{P}$, and nuclear issue opinion I. A balanced state exists in the following cases:

$-\mathrm{V}$ favors $\mathrm{P}, \mathrm{P}$ favors $\mathrm{I}$, and $\mathrm{V}$ favors $\mathrm{I}$;

$-V$ favors $P, P$ rejects $I$, and $V$ rejects $I$;

$-V$ rejects $P, P$ favors $I$, and $V$ rejects $I$;

$-V$ rejects $P, P$ rejects $I$, and $V$ favors $I$.

We speak of an imbalanced state when

$-\mathrm{V}$ favors $\mathrm{P}, \mathrm{P}$ rejects $\mathrm{I}$, and $\mathrm{V}$ favors $\mathrm{I}$;

$-\mathrm{V}$ favors $\mathrm{P}, \mathrm{P}$ favors $\mathrm{I}$, and $\mathrm{V}$ rejects $\mathrm{I}$;

$-V$ rejects $P, P$ rejects $I$, and $V$ rejects $I$;

$-V$ rejects $P, P$ favors $I$, and $V$ favors $I$.

We will restrict the area of application by taking into account only those states of (im)balance in which $\mathrm{V}$ actually has a party preference $\mathrm{P}$ and disregard those states of (im)balance in which $\mathrm{V}$ rejects a certain party $\mathrm{P}$, since with our survey material we can only construct states of (im)balance with the knowledge of a positive party choice.

\section{Methods}

From the 1986 National Election Study, we have used the following materials (see Appendix for detailed information):

The party component of the triad is operationalized in voting intention for CDA, PvdA, VVD, or D66 (wave 1) and actual vote (wave 2).

The issue opinion component is operationalized from the "nuclear plants" questions in both waves. As a rough approximation of a positive opinion toward 
nuclear plants we have taken scale positions 1-3; position 4 denotes a neutral posture, whereas positions 5-7 are held to indicate a negative opinion. ${ }^{2}$

The "unity" component is operationalized in the questions in both waves in which the respondents are asked to rate the four parties CDA, PvdA, VVD, and D66 on the same seven-point scale. A rating of a party between positions 1-3 indicates the perception of a positive opinion toward nuclear plants, position 4 the perception of a neutral stand, and positions 5-7 the perception of a negative opinion toward those plants.

In operational terms a balanced state exists in wave 1 among voters who intend to vote for PvdA, D66, CDA, and VVD, and whose opinions toward nuclear power plants are in agreement with their perception of the nuclear plant issue opinion of the party of their choice. An imbalanced state exists in wave 1 among voters who intend to vote for PvdA, D66, CDA, and VVD, and whose opinions on nuclear plants are in disagreement with their perception of the nuclear issue stand of the party they want to vote for. In both states in wave 1, respondents holding either neutral issue positions or viewing the parties as having neutral issue stands are excluded.

The different forms of change from wave 1 to wave 2 involve the following. A change of vote means a shift from an intention to vote for CDA, PvdA, VVD, or D66 to an actual vote for any other party, including the Dutch minor parties. A change of issue opinion indicates a shift from either a negative opinion to a neutral or a positive one, or from a positive opinion to a neutral or negative one. A change of party perception signifies a shift from a view of a party's position as negative to a view of that party as neutral or positive on the issue, or a shift from a view of a party's position as positive to a view of that party as neutral or negative.

\section{Results}

In wave 1, 571 respondents are selected; 483 of these are in a state of balance as defined above ( $85 \%$ ), while 88 respondents are in a state of imbalance $(15 \%)$. Table I indicates the changes among all respondents in the three variables between wave 1 and 2; in Tables II and III, it can be seen how the balanced and imbalanced states change from wave 1 to 2 .

The relatively small numbers of respondents in the two groups caution against an overconfident interpretation of the results; therefore we will report

${ }^{2} \mathrm{~A}$ trichotomization of the seven-point scale is consistent with Achen's observation that a respondent's genuine opinion on some issue is not a single point, but rather a distribution of points around some central position on a scale: "[R]espondents will not always respond the same way to the same question even if their attitude remain unchanged. A subject may say 'strongly agree' one time and 'agree' the next, simply because of the ambiguity of the question asked or because he is uncertain how strong is "strongly"' (Achen, 1975, p. 1220). 
Table I. All Voters, Wave 2

\begin{tabular}{lccccr}
\hline $\begin{array}{l}\text { Maintain issue opinion } \\
\text { Maintain party perception }\end{array}$ & $\begin{array}{c}\text { Change party } \\
\text { perception }\end{array}$ & $\begin{array}{c}\text { Change issue opinion } \\
\text { Maintain party perception }\end{array}$ & $\begin{array}{c}\text { Change party } \\
\text { perception }\end{array}$ & Total \\
\hline Maint. vote & $52 \%$ & $8 \%$ & $12 \%$ & $18 \%$ & $90 \%$ \\
Change vote & $5 \%$ & $2 \%$ & $2 \%$ & $1 \%$ & $10 \%$ \\
Total & $57 \%$ & $10 \%$ & $14 \%$ & $19 \%$ & $100 \%$ \\
$(\mathrm{~N}=571)$ & & & & & \\
\hline
\end{tabular}

only on the most significant differences between the balanced and imbalanced groups.

Turning to our empirical points, then, we can discern important differences between balanced and imbalanced voters. First, the state of balance is much more stable than the imbalanced one: $59 \%$ of the balanced voters in the first wave remain in an identical balanced state in wave 2 , while only $11 \%$ of the imbalanced voters in wave 1 persist in the same state of imbalance in the second wave.

Second, changes seem to come about in different forms in the two states. In the balanced state the most important change occurs by voters who maintain their party choice, while changing their issue opinion and party perception (19\%). This implies a shift toward a new state of balance and is consistent with the changes shown in Figure 2. The other changes either signify a transition to an imbalanced state (12\%), or the establishment of new (im)balanced states through a change in party choice (10\%).

The changes among the imbalanced voters provide an indication of the relative impact of policy voting, persuasion, and projection, as defined in terms of balance theory. We see that most change seems to come about through persuasion: a change in issue opinion while maintaining voting choice and issue perception of the preferred party (38\%). The second important form of change runs through projection: a change of party perception, with no altering of vote or issue opinion (27\%). The third, policy-based resolution, a change of party vote while keeping one's issue opinion and party perception, is obtained by only $2 \%$ of the imbalanced voters. Besides that, $11 \%$ of the imbalanced voters remain in this state, while $9 \%$ change to a new state of imbalance. Finally, $13 \%$ shift to a new state of (im)balance through a change of party preference.

Table II. Balanced Voters, Wave 2

\begin{tabular}{lrcccc}
\hline $\begin{array}{l}\text { Maintain issue opinion } \\
\text { Maintain party perception }\end{array}$ & $\begin{array}{c}\text { Change party } \\
\text { perception }\end{array}$ & $\begin{array}{c}\text { Change issue opinion } \\
\text { Maintain party perception }\end{array}$ & $\begin{array}{c}\text { Change party } \\
\text { perception }\end{array}$ & Total \\
\hline Maint. vote & $59 \%$ & $5 \%$ & $7 \%$ & $19 \%$ & $90 \%$ \\
Change vote & $5 \%$ & $2 \%$ & $1 \%$ & $2 \%$ & $10 \%$ \\
Total & $64 \%$ & $7 \%$ & $8 \%$ & $21 \%$ & $100 \%$ \\
$(\mathrm{~N}=483)$ & & & & & \\
\hline
\end{tabular}


Table III. Imbalanced Voters, Wave 2

\begin{tabular}{lrcccr}
\hline $\begin{array}{l}\text { Maintain issue opinion } \\
\text { Maintain party perception }\end{array}$ & $\begin{array}{c}\text { Change party } \\
\text { perception }\end{array}$ & $\begin{array}{c}\text { Change issue opinion } \\
\text { Maintain party perception }\end{array}$ & $\begin{array}{c}\text { Change party } \\
\text { perception }\end{array}$ & Total \\
\hline Maint. vote & $11 \%$ & $27 \%$ & $38 \%$ & $9 \%$ & $85 \%$ \\
Change vote & $2 \%$ & $4 \%$ & $8 \%$ & $1 \%$ & $15 \%$ \\
Total & $13 \%$ & $31 \%$ & $46 \%$ & $10 \%$ & $100 \%$ \\
$(\mathrm{~N}=88)$ & & & & \\
\hline
\end{tabular}

\section{CONCLUSIONS}

In this article I have discussed the differences between rational and rationalized voting, and I have argued that these forms of electoral decision making have not been properly analyzed within one consistent theoretical framework. I adopted a social psychological approach to the voting action, which was elaborated in Heider's balance theory. I was also able to select an actual "hot issue" and to test its impact on the vote under quasiexperimental conditions.

The first conclusion to be drawn is that the issue of nuclear power, forcefully brought to the attention of the electorate just before the start of the election campaign, does not seem to have had much influence upon the vote. The marginals of Table I show that, whereas one-third of the electorate changes its opinion on nuclear plants, and seven out of ten voters alter their perceptions of the major parties, only $10 \%$ deviate from their stated voting intention. Insofar as the Chernobyl accident has made an impact, it has not had one on the 1986 Dutch vote.

A second conclusion is that in this case persuasion and projection seem far more important means of conflict resolution than policy voting, which is remarkable given the high saliency of the issue involved. Our current results thus seem to provide little support for a Downsian, issue-oriented treatment of the vote, yet a definite conclusion on this matter must, of course, be postponed until these findings are repeated for other issues and tested under different conditions.

Further it may be argued that our approach constitutes a theoretical improvement over existing approaches. Instead of a collection of variables, loosely held together by some idiosyncratic combination of rational choice and social psychological perspectives, I have posited a psychological model of the voting action, in which persuasion, projection, and policy voting are redefined as modes of resolution of psychic conflict. For research purposes, this model may be easily extended to other factors influencing the voting decision, such as L-R ideology and party leaders. In a theoretical sense, the model attempts to synthesize different psychological currents which have emerged in recent and older electoral research (for a review see Visser, 1994).

Finally, it has been contended that, since most voters view the political 
world with little interest and involvement, they will in fact tolerate a great deal of imbalance among their political cognitions and evaluations. Our figures show that this is by and large not the case. In the first wave the number of balanced voters outweighs the imbalanced ones by a ratio of six to one. In the second wave the balanced state seems to be maintained much better than the imbalanced state; further, two out of every three imbalanced voters shift to a state of balance. The voter probably may not be rational, but this does not mean that his ideas and opinions about the political world are disorganized; it is only that the mode of their organization conforms more to psycho-logical than to formal logical requirements.

\section{ACKNOWLEDGMENTS}

The author wishes to thank Ank Michels and Kees Aarts (University of Twente), Robert Montjoy (Auburn University), and the participants of the workshop "Electoral Behavior" at the Dutch Political Science Association's 1993 Annual Meeting for their valuable comments on earlier drafts of this paper. Financial support for this research from the Netherlands Organization for the Advancement of Research (NWO) is gratefully acknowledged (grant nr. 430-214-032).

\section{APPENDIX: DATA AND VARIABLES}

The data for this paper originate from the Dutch National Election Studies (NES), large nationwide surveys held under the auspices of an interuniversity workgroup at every parliamentary election since 1971 . Selected was the NES of 1986. The following variables have been used:

-Voting intention

-Party voted for in most recent election

-Perceptions of the positions of CDA, PvdA, VVD and D66 on the nuclear power plants issue, measured on a seven-point scale ranging from 1 (more nuclear plants) to 7 (no nuclear plants)

-Respondent's preference on the nuclear power plants issue, measured on a seven-point scale ranging from 1 (more nuclear plants) to 7 (no nuclear plants)

The NES 1986 consisted of two waves of interviews: the preelection wave in March-April 1986, and the postelection wave immediately after the 1986 election, in May-June. Table IV indicates to which wave the different variables employed in this paper belong; the variable numbers refer to the numbers used in the codebooks, in which further information can be found (Van der Eijk et al., 
Table IV. NES Variables, 1986

\begin{tabular}{lcc}
\hline Variable & Wave 1 & Wave 2 \\
\hline Voting intention & V053 & \\
Party voted for, etc. & & V181 \\
Nuclear plants perception of CDA & V039 & V215 \\
Nuclear plants perception of PvdA & V040 & V216 \\
Nuclear plants perception of VVD & V041 & V217 \\
Nuclear plants perception of D66 & V042 & V218 \\
Nuclear plants respondent's preference & V043 & V219 \\
\hline
\end{tabular}

1988). Finally, note that the original collectors of the data do not bear any responsibility for the analyses or interpretations published in this paper.

\section{REFERENCES}

Achen, C. A. (1975). Mass political attitudes and the survey response. American Political Science Review, 69, 1218-1231.

Adorno, T. W., E. Frenkel-Brunswik, D. J. Levinson \& R. N. Sanford (1950). The Authoritarian personality. New York: Harper.

Berelson, B. R., P. F. Lazarsfeld \& W. N. McPhee (1954). Voting. A study of opinion formation in a presidential campaign. Chicago: University of Chicago Press.

Brody, R. A. \& B. I. Page (1972). The assessment of policy voting. American Political Science Review, 66, 450-458.

Downs, A. (1957). An economic theory of democracy. New York: Harper \& Row.

Festinger, L. (1957). A theory of cognitive dissonance. Stanford: Stanford University Press.

Festinger, L. (1964). Conflict, decision and dissonance. Stanford: Stanford University Press.

Frenkel-Brunswik, E. (1949). Intolerance of ambiguity as an emotional and perceptual personality variable. Journal of Personality, 18, 108-143.

Heider, F. (1946). Attitudes and cognitive organization. Journal of Psychology, 21, 107-112.

Koffka, K. (1935). Principles of Gestalt psychology. New York: Harcourt, Brace \& World.

Lane, R. E.(1973). Patterns of political belief. In J.N. Knutson (Ed.), Handbook of Political Psychology. San Francisco: Jossey-Bass.

Luskin, R. C. (1987). Measuring political sophistication. American Journal of Political Science, 31 , $856-899$.

Markus, G. B. \& P. E. Converse (1979). A dynamic simultaneous equation model of electoral choice. American Political Science Review, 73, 1055-1070.

Niemi, R. G. \& H. F. Weisberg (1984). Controversies in voting behavior. 2d ed. Washington: Congressional Quarterly Press.

Page, B. I. (1976). The theory of political ambiguity. American Political Science Review, 70, 742752.

Page, B. I. \& R. A. Brody (1972). Policy voting and the electoral process: The Vietnam War issue. American Political Science Review, 66, 979-995.

Page, B. I. \& C. C. Jones (1979). Reciprocal effects of policy preferences, party loyalties and the vote. American Political Science Review, 73, 1071-1090.

Rokeach, M. (1960). The open and closed mind. Investigations into the nature of belief systems and personality systems. New York: Basic Books.

Shively, W. P. (1980). The craft of political research. 2d ed. Englewood Cliffs, NJ: Prentice Hall. 
Sniderman, P. M., R. A. Brody \& P. E. Tetlock (1991). Reasoning and choice. Explorations in political psychology. Cambridge, MA: Cambridge University Press.

Van der Eijk, C., G. A. Irwin \& B. Niemöller (1988). Dutch parliamentary election study 1986. Amsterdam: Steinmetz Archives.

Van Holsteyn, J. J. M. (1987). Kernenergie, Tsjernobyl en de verkiezingen van 21 mei 1986. In J.J.M. Van Holsteyn, G.A. Irwin \& C. Van der Eijk (Eds.), De Nederlandse kiezer '86 (pp. 144-157). Amsterdam: Steinmetz Archives/SWIDOC.

Visser, M. (1994). The Psychology of Voting Action: On the Psychological Origins of Electoral Research, 1939-1964. Journal of the History of the Behavioral Sciences, 30, 43-52. 